\section{G72 WHO IS MOST AT RISK FROM CORONARY ARTERY ANEURYSMS IN KAWASAKI DISEASE IN A UK POPULATION?}

1J Laidlaw, ${ }^{2}$ AM George, ${ }^{1,2}$ RMR Tulloh. 'Bristol Royal Hospital for Children, Bristol, UK; ${ }^{2}$ University of Bristol, Bristol, UK

\subsection{6/archdischild-2018-rcpch.70}

Background The increasing incidence of Kawasaki disease $(\mathrm{KD})$ in the UK is associated with increasing numbers of children with coronary artery aneurysms (CAA) as sequelae $(24 \%$ of children despite immunoglobulin, IVIG). We wish to determine a system of recognising those at presentation who may need additional therapy since it has been shown that systems in Japan (eg Kobayashi) do not apply to the UK or USA.

Methods All children with KD presenting to any hospital in our region over a time period of 16 years were reviewed, presenting from 2001-2017. Only children with postcodes in our region were included, to avoid any sample bias. Demographic and laboratory characteristics were obtained and the correlation with CAA was noted. The data were analysed for sex, age at diagnosis, clinical features of KD and laboratory parameters (full blood count, CRP, liver function tests, albumin, and sodium).

Results 493 children were seen without case selection during this time period. Of these 105 had CAA and 388 did not. The rate of diagnosis increased during the time period, as did the numbers with CAA. Demographic data showed the overall incidence of children with CAA was 22\%, two-thirds were male and those with CAA were younger compared to those without: median 823 vs 1478 days, $p=0.01$. If there was a lower platelet count 323 vs $419 \times 10^{9} / \mathrm{L}, \mathrm{p}=0.02$, higher neutrophil count 9.3 vs $6.6 \times 10^{6} / \mathrm{L}, \mathrm{p}=0.0001$, and higher CRP 181 vs $102 \mathrm{mg} / \mathrm{L}, \mathrm{p}=0.005$, but not serum sodium or liver function tests, these were associated with CAA. It was noted that patients with KD were more likely to come from rural than urban areas. Younger children under 6 months were more likely to have giant aneurysms and to have atypical KD. Conclusions In this large defined catchment area, we have demonstrated risk factors that are typical of children in a UK population. Although not a prospective study, this data suggests those who are most likely to develop CAA and to be resistant to IVIG therapy. More formal analysis is needed to determine if this is consistent with multi-variate analysis but seems a good early indicator.

\section{G73 A SURVEY OF UK PAEDIATRICIANS' AWARENESS AND ENQUIRY REGARDING ADVERSE CHILDHOOD EXPERIENCES (ACES)}

P Venkatesan, O Akindolie. Department of Child Health, King's College Hospital, London, UK

\subsection{6/archdischild-2018-rcpch.71}

Aims The publication of the pioneering Adverse Childhood Experiences (ACEs) study, ${ }^{1}$ has resulted in an increasing body of evidence demonstrating that exposure to ACEs has a significant impact on adult health outcomes. Our aim was to evaluate the level of awareness and enquiry regarding ACEs amongst paediatricians in clinical practice in the UK.

Methods An electronic questionnaire was distributed to a sample of hospital and community based paediatricians in practice in the UK. Details of the original ACE study were provided including the 10 ACEs:
Abuse:

- Physical

- Emotional

- Sexual

Neglect:

- Physical

- Emotional

Household Member:

- Mental illness

- Substance Misuse

- Incarceration

- Maternal Domestic Violence

- Parental Divorce or Separation

Questions were subsequently posed regarding the current level of routine enquiry and management of ACEs in paediatric clinical consultations.

Results The survey resulted in 74 completed questionnaires. Prior to this survey, $50 \%$ of the respondents were not familiar with the findings of the original ACEs study whilst $16.7 \%$ reported being very familiar with the findings.

Enquiry related to ACEs in paediatric clinical consultations (table 1):

Abstract G73 Table 1 Percentage frequency of enquiry regarding aces in paediatric consultations

\begin{tabular}{|c|c|c|c|c|c|}
\hline & $\begin{array}{l}\text { When relevent to } \\
\text { clinical } \\
\text { presentation }\end{array}$ & Usually & Sometimes & Rarely & Never \\
\hline Physical Abuse & 71.6 & 5.4 & 18.9 & 2.7 & 1.4 \\
\hline Emotional Abuse & 66.2 & 5.4 & 18.9 & 6.8 & 2.7 \\
\hline Sexual Abuse & 74.3 & 1.4 & 9.5 & 13.5 & 1.4 \\
\hline Physical Neglect & 62.2 & 13.5 & 16.2 & 6.8 & 1.4 \\
\hline Emotional Neglect & 67.6 & 8.1 & 14.9 & 5.4 & 4.1 \\
\hline $\begin{array}{l}\text { Mental Illness in a } \\
\text { Household Member }\end{array}$ & 39.2 & 24.3 & 32.4 & 2.7 & 1.4 \\
\hline $\begin{array}{l}\text { Substance Misuse in } \\
\text { a Household Member }\end{array}$ & 44.6 & 16.2 & 31.1 & 6.8 & 1.4 \\
\hline $\begin{array}{l}\text { Incarceration of a } \\
\text { Household Member }\end{array}$ & 35.1 & 8.1 & 17.6 & 23 & 16.2 \\
\hline $\begin{array}{l}\text { Maternal Domestic } \\
\text { Violence }\end{array}$ & 52.7 & 12.2 & 20.3 & 14.9 & 0 \\
\hline $\begin{array}{l}\text { Parental Divorce or } \\
\text { Separation }\end{array}$ & 18.9 & 60.8 & 16.2 & 2.7 & 1.4 \\
\hline
\end{tabular}

Conclusion Whilst knowledge of the ACEs study appears to be relatively low amongst the sampled group of UK paediatricians, it is reassuring that enquiry related to specific ACEs is already embedded in clinical practice. This is supported by the presence of an excellent and established range of allied services available for onward referral and definitive management. The American Academy of Paediatrics (AAP) has published a position statement supporting routine screening for ACEs in the USA. ${ }^{2}$ This has resulted in a gathering of momentum with an ACE focussed approach to paediatrics supported by the National Paediatric Practice Community (NPPC). ${ }^{3}$

The findings of this survey represent a significant opportunity. A compelling case is made for child advocacy and an evidence base for sustained investment in all allied services which 